\title{
Zn(II) and Cd(II) Coordination Dimers Based on Mixed Benzodioxole-Carboxylate and N-Donor Ligands: Synthesis, Characterization, Crystal Structures and Photoluminescence Properties
}

3

4 5

6

7

8

9

10

11

12

13 a] M. Guerrero, S. Vázquez, J. A. Ayllón, J. Pons

Departament de Química Universitat Autònoma de Barcelona 08193-Bellaterra, Barcelona, Spain Fax: 34-93 5813101

\section{E-mail: Josefina.Pons@uab.cat}

[b] M. Guerrero

Departament de Física Universitat Autònoma de Barcelona 08193-Bellaterra, Barcelona, Spain

$$
\text { [c] T. Calvet }
$$

Cristal·lografia, Mineralogia i Dipòsits Minerals Universitat de Barcelona Martí i Franquès s/n, 08028-

$$
\text { Barcelona, Spain }
$$

[d] M. Font-Bardia

6 Unitat de Difracció de Raig-X Centres Científics i Tecnològics de la Universitat de Barcelona

7 (CCiTUB) Universitat de Barcelona Solé i Sabarís, 1-3, 08028-Barcelona, Spain 


\section{ABSTRACT:}

35

36 Four new compounds, formulated as [Zn(m-Pip)2(3-Phpy)]2 (1), [Zn(m-Pip)2(4-Phpy)]2 (2), [Cd(m-

37 Pip)(Pip)(3-Phpy)2]2 (3) and [Cd (m-Pip)(Pip)(4-Phpy)2]2 (4) (HPip=1,3-benzodioxole-5-carboxylic

38 acid; Phpy= phenylpyridine), have been successfully assembled based on rigid carboxylate/pyridine

39 ligands. These four compounds have been fully characterized by analytical and spectroscopic methods.

40 The aim of the present study is to investigate the structural effect and the influence of the size of metal

41 on the class, geometry and type of coordination of the carboxylate ligands (syn-syn, syn-anti) in the final

42 3D-arrangements of the structures. Finally, luminescence properties of these new four coordination

43 dimers have been investigated.

44

45

46 
49 During the last years, the synthesis of metal-organic coordination compounds has attracted enormous

50 interest not only for their intriguing structural diversity but also their potential application in catalysis,

51 drug delivery, magnetism and so on.[1] Studies in this field permit relationships between the structure of

52 the compounds and their properties. Generally, the three dimensional structure of complexes depends on

53 the coordination preferences of the metal center and the functionality/ versatility of the ligands.

54 Furthermore, additional factors as hydrogen bonding or p-p stacking interactions, solvent molecules of

55 media, counterions or the metal salt:organic ligand ratio also influence the final disposition of the

56 architectures of the compounds.[2]

57 Carboxylate ligands have been used as multifunctional tectons, not only for their ability in the formation

58 of covalent bonds with metal ions, but also for supramolecular interactions.[3] Heterocyclic nitrogen

59 donors, such as pyridine, pyrazole, and related molecules, are also fascinating ligands. As a result,

60 during the last years a great number of coordination complexes with diverse frameworks: one

61 dimensional (1D) chains, twodimensional (2D) layers or three dimensional (3D) cavities have been

62 described in the literature.[4]

$63 \mathrm{Zn}(\mathrm{II})$ and $\mathrm{Cd}(\mathrm{II})$ ions with $\mathrm{d} 10$ electron configuration are particularly suitable for the construction of

64 polynuclear compounds. These exhibit a variety of coordination numbers and arrangements varying

65 from tetrahedral to octahedral. The $\mathrm{Zn}(\mathrm{II})$ and $\mathrm{Cd}(\mathrm{II})$ compounds can readily form mononuclear and

66 binuclear compounds and all kinds of architectures such as 1D, 2D and 3D structures. These metals are

67 particularly promising due to their interesting luminescent properties[5] and broad applications in the

68 biological area.[6] In particular, mononuclear and binuclear zinc carboxylates complexes are of great

69 importance to study them as biological model compounds.[7] The versatility in many biological systems

70 is ascribed to the variety and flexibility of the different coordination modes of the carboxylate ligands.

71 Interestingly, the paddle-wheel type of structure from $\mathrm{Zn}$-carboxylate and $\mathrm{Cd}$-carboxylate is already

72 reported in the literature; however, it is not very clear on what conditions such complexes are formed.[8]

$73 \mathrm{Cu}$ (II) compounds with 1,3-benzodioxole-5-carboxylic acid (HPip)[9] and N-derived pyrazole

74 ligands[10], were recently designed in our group. As a continuation of this study we chose $\mathrm{Zn}(\mathrm{II})$ and

$75 \mathrm{Cd}(\mathrm{II})$ as metals to construct different frameworks with 3-phenylpyridine (3-Phpy) and 4-phenylpyridine

76 (4- Phpy), and reported two Zn(II), [Zn(m-Pip)2(3-Phpy)]2 (1) and [Zn (m-Pip)2(4-Phpy)]2 (2) and two

$77 \mathrm{Cd}(\mathrm{II}),[\mathrm{Cd}(\mathrm{m}-\mathrm{Pip})(\mathrm{Pip})(3-\mathrm{Phpy}) 2] 2$ (3) and [Cd(m-Pip)(Pip)(4-Phpy)2]2 (4) coordination dimers in

78 which the metal has an important role on their structures and properties.

79 


\section{Synthesis and general characterization}

83 Complexes 1-4 were prepared in $\mathrm{MeOH}$ at room temperature via combination of the

$\mathrm{M}(\mathrm{MeCO}) 2 \cdot 2 \mathrm{H} 2 \mathrm{O}(\mathrm{M}=\mathrm{Zn}$ or $\mathrm{Cd}$ ) salt reagents, 3-phenylpyridine (3-Phpy) or 4-phenylpyridine (4Phpy), and 1,3-benzodioxole-5-carboxylic acid (Pyperonylic acid, HPip) ligands (Scheme 1). In these reactions the acetate anions were displaced by carboxylate groups. The corresponding crystals suitable for X-ray crystallographic analysis were grown via slow evaporation of their solution. The new four complexes were characterized via elemental analysis, infrared (IR), Raman, nuclear magnetic resonance (NMR) spectroscopy and single-crystal X-ray diffraction. The elemental analysis for compounds 1-4 are in agreement with their formula. The IR spectra of 1-4 display the characteristic carboxylate bands in the range of 1641-1539 cm 1 for nas(CO2) and at 1489-1384 cm 1 for ns(CO2) and were fully consistent with their formulations (SI Figure S1-S4). For 1-4, the differences between nas $(\mathrm{CO} 2)$ and $\mathrm{ns}(\mathrm{CO} 2)$ are 162, 160,167, and $171 \mathrm{~cm}$ 1, respectively, indicating a bidentate bridging coordination mode for the carboxylates.[11] Moreover, for compounds 3 and 4, other D values of nas $(\mathrm{CO} 2)$ and $\mathrm{ns}(\mathrm{CO} 2)$ were observed (115 and $118 \mathrm{~cm} \quad 1$, respectively), indicating the presence of bidentate chelate carboxylate groups in both complexes.[11] Absence of a band at 1720-1690 cm 1 in the four spectra indicates that the carboxylic acids are deprotonated in the corresponding compounds. The bands attributable to the aromatics groups $\mathrm{n}(\mathrm{C}=\mathrm{C}) \operatorname{ar}, \mathrm{n}(\mathrm{C}=\mathrm{N})$ ar, $\mathrm{d}(\mathrm{C} H)$ ip and $\mathrm{d}(\mathrm{C} H)$ oop are also observed. The IR spectral data thus clearly lend support to the structures determined by the X-ray diffraction method.

Raman spectroscopy experiments were also performed to further characterize the compounds. The most relevant bands of the spectra of the four compounds and their assignations are shown in Supporting Information (SI, Figure S5-S8).[12] Compounds 1-4 have similar Raman spectra, showing comparable bands at approximately the same wavelength. On the high wavelength part of the spectra only two signals can be observed, at 3082-3071 $\mathrm{cm}$ 1, assigned to the $=\left(\begin{array}{ll}C H \\ \text { H }\end{array}\right)$ vibration of aromatic carbons and a less prominent band at 2906-2894 $\mathrm{cm} 1$ assigned to the $\mathrm{C} \mathrm{H}$ vibration of the dioxole group of the Pip ligands. Two strong signals at $1632-1626 \mathrm{~cm} \quad 1$ and $1613-1585 \mathrm{~cm} \quad 1$, respectively, are assigned to the $\mathrm{C}=\mathrm{N}$ vibration of the 3-phpy and 4-phpy ligands and to the $\mathrm{C}=\mathrm{O}$ vibrations of the carboxylates of the Pip ligands. A band between $1300-1297 \mathrm{~cm} 1$ is assigned to the $\mathrm{C} N$ vibration of the 3-phpy and 4-phpy, and at 810-807 cm 1 the C O-C vibration of the dioxole group of the Pip ligands can be observed. On the low wavelength part of the spectra, strong and broad bands appear for the four compounds, corresponding to the lattice vibrations of the crystals. 
118 The reaction of $\mathrm{Zn}(\mathrm{MeCO} 2) 2 \cdot 2 \mathrm{H} 2 \mathrm{O}$, 1,3-benzodioxole-5-carboxylic acid (HPip) and 3-phenylpyridine (3-Phpy) (1) or 4-phenylpyridine (4-Phpy) (2), in methanol at room temperature with a ratio of 1:2:4, leads to [Zn(m-Pip)2(3-Phpy)]2 (1) and [Zn(m-Pip)2 (4-Phpy)]2 (2). The structural determination revealed that $\mathrm{Zn}(\mathrm{II})$, Pip and 3-Phpy or 4-Phpy are present in 1:2:1 ratio in both complexes. A perspective view of 1 and 2 is shown in Figure 1 (left and right, respectively). Selected bond distances and angles are provided in Table 1.

The crystal structure of 1 and 2 consists of two independent centrosymmetric tetracarboxylate in a synsyn configuration bridged dimers. The $\mathrm{Zn}$ atoms adopt a [ $\mathrm{ZnO} 4 \mathrm{~N}]$ coordination mode with four oxygen atoms from four different 1,3- benzodioxole-5-carboxylate units and one nitrogen atom of the 3-Phpy or 4-Phpy ligands. The carboxylates display a paddlewheel-like arrangement about the $\mathrm{Zn} \cdots \mathrm{Zn}$ axis. The tetracarboxylate bridging framework can accommodate a metal-metal separation up to 3.452 [ . [13] The $\mathrm{Zn} \cdots \mathrm{Zn}$ separation in compounds 1 and 2 are 2.9253(9) and 2.9692(2) [ , respectively. Each Zn(II) ion adopts a slightly distorted square-pyramidal environment $(\mathrm{t}=0.0035$ (1) and $0.042,0.045$ (2))[14], coordinated equatorially to four carboxylate oxygen atoms [ $\mathrm{Zn} \quad$ O: $2.018-2.077$ (1); 2.0092-2.0614 [ (2)] and apically to the 3-Phpy or 4- Phpy [Zn N: 2.045 (1); 2.0396 and 2.0465 (2)]. The values are comparable with the reported values in $[\mathrm{Zn}(\mathrm{L} 1) 2(\mathrm{ql})] 2(\mathrm{~L} 1=\mathrm{p}$-chlorophenoxyacetic acid; $\mathrm{ql}=$ quinoline $)[15],[\mathrm{Zn}(\mathrm{m}-4-\mathrm{OBz}) 2$ (py)]2,[16] [Zn(m-4-OBz)2(py)]2·0.5CH3OH (4-OBz=pchlorobenzoic acid; py=pyridine)[17] and [Zn(L2)2(L1)]2 (L2=1,1':3',1' '-terphenyl- 4,4',4',,6'tetracarboxylic acid; L1=4-amino-3,5-diphenyl-1Hpyrazole).[18]

\section{Crystal structure of $\mathrm{Cd}(\mathrm{II})$ complexes 3 and 4}

Compounds 3 and 4 were prepared by reaction of $\mathrm{Cd}(\mathrm{MeCO} 2) 2 \cdot 2 \mathrm{H} 2 \mathrm{O}, 1$,3-benzodioxole-5-carboxylic acid (HPip) and 3-phenylpyridine (3-Phpy) (3) or 4-phenylpyridine (4-Phpy) (4), in MeOH solvent at room temperature with a ratio of 1:2:4, yielding [Cd(m-Pip)(Pip)(3-Phpy)2]2 (3) and $[\mathrm{Cd}(\mathrm{m}-$ Pip)(Pip)(4-Phpy)2]2 (4). Interestingly, the structural determination revealed that Cd(II), Pip and 3-Phpy or 4-Phpy are present in ratio 1:2:2 in both complexes while in 1 and 2 ( $\mathrm{Zn}$ (II) complexes) the ratio was 1:2:1. A perspective view of 3 and 4 is shown in Figure 2 (left and right, respectively). Selected bond distances and angles are provided in Table 1.

The crystal structure of 3 and 4 consists of two independent centrosymmetric dicarboxylate bridged dimers. An asymmetric unit of [Cd(m-Pip)(Pip)(dpy)2]2 (dpy=3-Phpy, 4-Phpy) contains two sixcoordinated Cd(II) ions, two Pip bridges, two Pip bidentate chelate ligands, and two lattice dpy molecules. Both $\mathrm{Cd}$ atoms adopt a [CuO4N2] coordination mode with four oxygen atoms from four different Pip units and two nitrogen atoms of the dpy ligands coordinated in trans disposition. In compound 4, the phenyl of 4-Phpy molecule is disordered. The bridging carboxylate ligands show an asymmetric syn-anti coordination mode, with Cd O distances (Cd O5 2.2967(9) ] , Cd O6

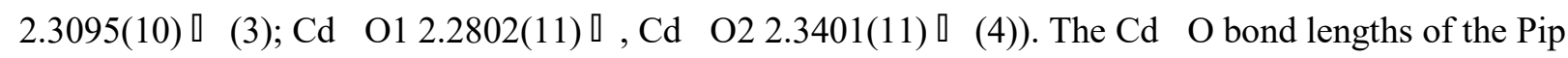


chelate ligand are longer than the corresponding Pip bridging mode (Cd-O(1) $2.4267 \square, \mathrm{Cd}-\mathrm{O}(2) 2.3659$ (9) $]$ (3) and $\mathrm{Cd}-\mathrm{O}(5) 2.4257 \mathrm{C}, \mathrm{Cd}-\mathrm{O}(6) 2.3490 \square$ (4)). The angles around the $\mathrm{Cd}$ atom are 55.13(3)173.77(4)8 (3) and 55.34(3)-178.06(5)8 (4). Interestingly, Zn(II) compounds (1 and 2) present the same dimer paddle-wheel structure with 3-Phpy and 4-Phpy, while Cd(II) atoms have the same octahedral dimer coordination ( 3 and 4). This clearly indicates that the metal atom influences the coordination of the ligands, while the difference on the phenilpyridine ligands does not present significant influence on the core of the compounds.

\section{Extended Structures of 1-4complexes}

Molecular solids, which consist of coordination complexes assembled in the solid state as a consequence of non-covalent bonding, are a developing field of research due to their potential applications in diverse areas.[19] Among non-covalent interactions, hydrogen bonding interaction is one of the major cohesive forces in supramolecular aggregation and plays the most important role in material science.[20] In all the new four compounds, the binuclear units are linked together via hydrogen bond interactions involving the Pip ligands forming a compact 3D supramolecular network. In compound 1, an oxygen from the carboxylate group forms two different hydrogen bonds: C24H24B $\cdots \mathrm{O} 1$ (2.486 ), interacting with a hydrogen from the dioxole group of an adjacent Pip ligand, and C26-H26 $\cdots \mathrm{O} 1$ (2.486 [), interacting with a hydrogen from the aromatic ring of another adjacent Pip ligand. These interactions are responsible for the expansion in the crystallographic in directions $a$ and $b$.

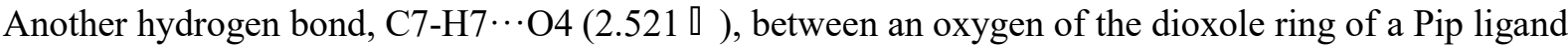
and a hydrogen from the aromatic ring of the 3-Phpy, is responsible for the final expansion in direction $\mathrm{c}$ (Figure 3, Table 2).

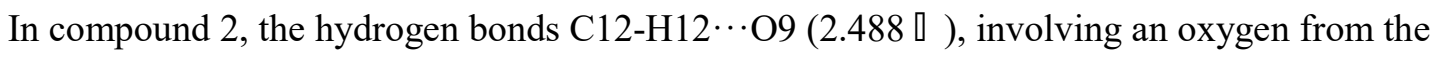
carboxylate group and a hydrogen from an adjacent Pip unit, and C50-H50 $\cdots \mathrm{O} 11$ (2.524 $\square$ ), connecting the dioxole ring of the Pip ligand and a hydrogen from the aromatic ring of a 4-Phpy, and a $\mathrm{p} \cdots \mathrm{H}$ interaction, $\mathrm{C} 44-\mathrm{H} 44 \cdots \mathrm{Cg} 1(3.029 \square, \mathrm{Cg} 1=\mathrm{C} 2-\mathrm{C} 8)$, are responsible for the expansion in the crystallographic $\mathrm{a}$ and $\mathrm{b}$ directions. Final expansion in the $\mathrm{c}$ direction is caused by another hydrogen

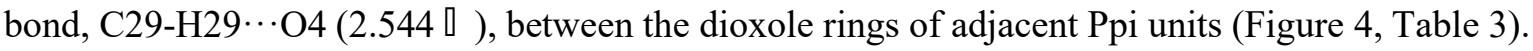
In compound 3, an oxygen from the carboxylate group of the chelate Pip unit forms a hydrogen bond

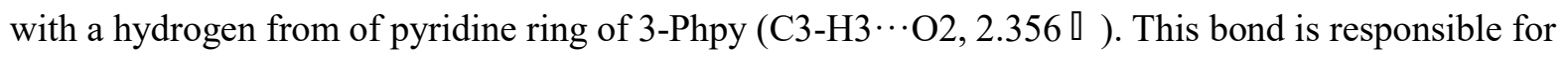
the expansion in the crystallographic a direction. The other oxygen of the carboxylate group of the same chelate bonding Pip forms another hydrogen bond by linking with a hydrogen of the dioxole group of the chelate Pip of a different binuclear unit (C28-H28B $\cdots \mathrm{O} 1,2.468 \mathrm{C})$. This bond expands the structure in the direction that makes an angle of ca. 308 with the bc plane. A short contact between the carbon atom of the dioxole group of the chelate Pip with a hydrogen of the aromatic ring of a binding piperolinate $(\mathrm{C} 34-\mathrm{H} 34 \cdots \mathrm{C} 28$, 
In compound 4, an oxygen from the carboxylate group of a chelate Pip unit forms two hydrogen bonds, one with a hydrogen from the phenyl ring of a 4-Phpy ligand (C18- H18 $\cdots \mathrm{O} 6,2.547 \mathrm{)}$ ), and another with a hydrogen from the pyridine ring of the same 4-Phpy ligand (C15-H15 $\cdots \mathrm{O} 6,2.509 \square)$. The same hydrogen from the pyridine ring forms another hydrogen bond with an oxygen from the carboxylate

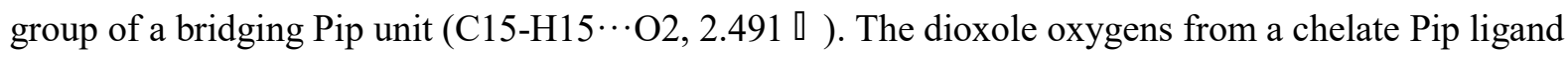
form one hydrogen bond each, one with a hydrogen of the phenyl ring of a 4-Phpy ligand of an adjacent

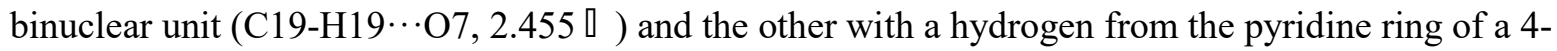

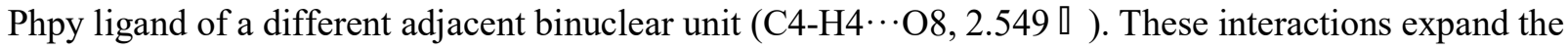
structure in the a and c directions, forming layers on the ac plane. A hydrogen-hydrogen contact (C16$\mathrm{H} 16^{\cdots}{ }^{\mathrm{H} 16}-\mathrm{C} 16$ ', $2.093 \square$ ) further supports the expansion in the a direction, while a second hydrogenhydrogen contact (C13-H13 $\cdots \mathrm{H} 22-\mathrm{C} 22,2.270 \square)$ is responsible for the final expansion of the structure in the $\mathrm{b}$ direction. (Figure 6, Table 3).

\section{NMR experiments}

1HNMR spectra of the complexes 1-4 were recorded in DMSOd6 (Figure 7) and clearly show the signals of two kind of ligands: 1,3-benzodioxole-5-carboxylate (Pip) and 3-phenylpyridine (3-Phpy) (1, 3 ) or 4-phenylpyridine (4-Phpy) $(2,4)$. The Pip ligand is coordinated through the carboxylate group, while the derivatives amine ligands are coordinated to the metallic center by the nitrogen atom. HMQC spectra were used to assign the signals (SI, Figure S9-S12).

The 1HNMR spectra present three signals between 6.84 and $7.52 \mathrm{ppm}$, assigned to the protons of the dioxole group. Other signals are attributable to the protons of the pyridyl group (3- Phpy or 4-Phpy). The chemical shifts of ortho-H pyridyl protons are consistent with the presence of N-coordinated of thepyridyl groups. The rest of the signals correspond to phenyl groups (Pip and 3-Phpy or 4-Phpy). $13 \mathrm{C}\{1 \mathrm{H}\}$ NMR spectra could not be recorded for either complex owing to the very low solubility in common solvents. NMR data are reported in experimental section.

\section{Photoluminescence properties}

Emissive coordination compounds are of great interested currently due to their various applications in the areas of chemical sensors and photochemistry.[21]

In order to clarify the structural modification effects of the Pip ligand on the complexes, we have performed luminescence spectroscopy. Figure 8 shows the emission spectra of the Pip ligands in a concentration of $10 \quad 6 \mathrm{M}$ and its complexes 1-4 in a concentration of $107 \mathrm{M}$ in methanol at $298 \mathrm{~K}$. The fluorescence emission spectra of the complexes were carried out with an excitation wavelength of $289 \mathrm{~nm}$. The fluorescence intensity of these complexes is larger than that of the free ligand. This could be explained by the rigidity enhancement of the coordinated ligand in these complexes.[22] For the four complexes, the quantum yields are quite similar, and exhibit the same fluorescence spectra, in this case, the fluorescence intensity is enhanced by a factor between $\sim 60$ and $\sim 90$, in comparison with the ligand. 
227 The free HPip ligand displays a weak luminescence at ca. $345 \mathrm{~nm}$ and the derivatives amines (3-Phpy 228 and 4-Phpy) do not present luminescence properties. It is important to take into account that the 229 fluorescent bands of the four complexes are slightly bathochromically shifted (352 nm), indicating the 230 lengthening of the conjugate p-electronic system in complexes 1-4. The fluorescence intensity of the 231 obtained complexes does not change for a long time (more the $72 \mathrm{~h}$ ); this is very promising for the use 232 of the corresponding ligand for the sensitive luminescence determination for heavy metals.[23] 
236 Four new 3D compounds [Zn(m-Pip)2(3-Phpy)]2 (1), [Zn(m-Pip)2 (4-Phpy)]2 (2), [Cd(m-Pip)(Pip)(3-

237 Phpy)2]2 (3) and [Cd(m-Pip)(- Pip)(4-Phpy)2]2 (4) (HPip=1,3-benzodioxole-5-carboxylic acid;

238 Phpy=phenylpyridine), with diverse structures were successfully obtained when combining carboxylate

239 and pyridine ligands. The four compounds have been fully characterized by elemental analysis, infrared

240 (IR), Raman, nuclear magnetic resonance (NMR) spectroscopy and single-crystal X-ray diffraction. It

241 has been demonstrated that the size of the metal ( $\mathrm{Zn}$ (II) vs. Cd(II)) clearly influences the coordination of

242 the Pip ligand, while the difference on the phenilpyridine ligands does not present significant influence

243 on the core of the compounds. The complexes are assembled to form three dimensional supramolecular

244 frameworks by hydrogen-bonding interactions. The supramolecular structures of the four compounds

245 are quite different, indicating that the different phenilpyridine ligands are able to tune the intermolecular

246 contacts. In all cases, the dioxole group of the Pip ligands was responsible of most of the intermolecular

247 interactions. Finally, a great enhancement of the fluorescence intensity was observed for the Cd(II)

248 compounds, indicating that they may be potential candidates for lumines- cent materials. In short, this

249 study provides new approach to construct new functional materials. 


\section{ACKNOWLEDGEMENTS}

252

253 This work is partially financed by the Spanish National Plan of Research CTQ2014-56324 and 254 MAT2015-65756-R, and by the 2014SGR260 and 2014SGR377 projects from the Generalitat de 255 Catalunya. Thanks to Dr. Oscar Palacios for lending the fluorometer and Dr. Santiago Maspoch for 256 lending the Raman spectrometer. M. Guerrero acknowledges the support of the Secretary for 257 Universities and Research of the Government of Catalonia and the COFUND Programme of the Marie 258 Curie Actions of the 7th R\&D Framework Programme of the European Union for the 'Beatriu de Pinos' 259 contract (2013 BP B 00077).

260 
261 Keywords: Cd(II) dimer · Piperonylic acid - Supramolecular networks · Zinc(II) paddle-wheel 
[1] a) D. L. Reger, A. Leitner, M. D. Smith, Cryst. Growth Des. 2015, 15, 5637-5644; b) A. Carn】 , C. Carbonell, I. Imaz, D. Maspoch, Chem. Soc. Rev. 2011, 40, 291-305; c) T. Komatsu, J. M. Taylor, H. Kitagawa, Inorg. Chem. 2016, 55, 546-548.

[2] a) J. J. Perry IV, J. A. Perman, M. J. Zoworotko, Chem. Soc. Rev. 2009, 38, 1400-1417; b) K. Harris, Q.-F. Sun, M. Fujita, Comprehensive Inorganic Chemistry II 2013, 8, 31-57; c) N. Ahmad, A. H. Chugtai, A. H. Younus, F. Verpoort, Coord. Chem. Rev. 2014, 280, 1-27; d) Z.-J. Lin, M. Hong, R. Cao, Chem. Soc. Rev. 2014, 43, 5867-5895.

[3] R. Chakrabarty, P. S. Mukherjee, P. J. Stang, Chem. Rev. 2011, 111, 6810-6918.

[4] a) S. Burattini, B. W. Greenland, D. H. Merino, W. Wang, J. Seppala, H. M. Colghoun, W. Hayes, M. E. Mackay, L. W. Hamley, S. J. Rowan, J. Am. Chem. Soc. 2010, 132, 12051-12058; b) J. R. Karra, Y. G. Huang, K. S. Walton, Cryst. Growth Des. 2013, 13, 1075-1081.

[5] a) M. Guerrero, J. Pons, J. Ros, M. Font-Bard a, O. Vallcorba, J. Rius, V. Branchadell, A. Merkoc, ,i, CrystEngComm 2011, 13, 6457-6470; b) M. Guerrero, J. Pons, M. Font-Bard a, T. Calvet, J. Ros, Aust. J. Chem. 2010, 63, 958-964; c) Z.-H. Yan, W. Wang, L. Zhang, X. Zhang, L. Wang, RSC Advances 2015, 5, 16190-16198; d) Y. Cui, Y. Yue, G. Qian, B. Chen, Chem. Rev. 2012, 112, 1126-1162.

[6] a) F. E. Jacobsen, J. A. Lewis, S. M. Cohen, J. Am. Chem. Soc. 2006, 128, 3156-3157; b) H. S. He, D. T. Puerta, S. M. Cohen, K. R. Rodgers, Inorg. Chem. 2005, 44, 7431-7442; c) L. M. Berreau, Comprehensive Inorganic Chemistry II 2013, 3, 179-205.

[7] a) R. H. Holm, P. Kennepohl, E. I. Solomon, Chem. Rev. 1996, 96, 2239 2314; b) L. Kuckova, K. Jomova, A. Svorcova, M. Valko, P. Segl'a, J. Moncol, J. Korisek, Molecules 2015, 20, 2115-2137; c) K. L. Haas, K. J. Franz, Chem. Rev. 2009, 109, 4921-4960.

[8] a) Y. Ling, Z. Chen, H. Zheng, Y. Zhou, L. Weng, D. Zhao, Cryst. Growth Des. 2011, 11, $2811-$ 2816; b) Y.-H. Zhou, J. Inorg. Organomet. Polym. 2015, 25, 535-543; c) J. Li, Y. Peng, H. Liang, Y. Yu, B. Xin, G. Li, Z. Shi, S. Feng, Eur. J. Inorg. Chem. 2011, 2712-2719.

[9] J. Soldevila-Sanmart n, J. A. Ayll[ n, T. Calvet, M. Font-Bard a, C. Domingo, J. Pons, Inorg. Chem. Commun. 2016, 71, 90-93.

[10] a) A. M. LI pez Marzo, M. Guerrero, T. Calvet, M. Font-Bard a, E. Pellicer, M. D. Bar】 , J. Pons, J. Sort, RSC Advances 2015, 5, 32369-32375; b) A. M. L】 pez Marzo, M. Guerrero, T. Calvet, M. Font-Bard a, J. Pons, Inorg. Chem. Commun. 2015, 55, 51-55.

[11] a) G. B. Deacon, R. J. Phillips, Coord. Chem. Rev. 1980, 33, 227-250; b) K Nakamoto, Infrared and Raman Spectra of Inorganic and Coordination Compounds. Applications in Coordination, Organometallic, and Bioinorganic Chemistry, 6th ed. New York, USA, 2009.

[12] B. Lambert, Introduction to Organic Spectroscopy, Macmillan, New York, USA, 1978.

[13] T. Allman, R. C. Goel, N. K. Jha, A. L. Beauchamp, Inorg. Chem. 1984, 23, 914-918.

[14] W. Addison, T. N. Rao, J. Chem., Soc. Dalton Trans. 1984, 1349-1356.

[15] S. Jin, H. Liu, G. Chen, Z. An, Y. Lou, K. Huang, D. Wang, Polyhedron 2015, 95, 91-107. 
[16] A. Karmakar, R. J. Sarma, J. B. Baruah, Inorg. Chem. Commun. 2006, 9, 1169-1172.

[17] D. Dey, S. Roy, R. N. D. Purkayastha, R. Pallepogu, L. Male, V. Mckee, J. Coord. Chem. 2011, 7, 1165-1176.

[18] K. Pal, S. Neogi, P. K. Bharadwaj, Chem. Eur. J. 2015, 21, 16083-16090. [19] a) G. J. O. Beran, Chem. Rev. 2016, 116, 5567-5613; b) M. Guerrero, J. Pons, M. Font-Bardia, T. Calvet, J. Ros, Polyhedron 2010, 29, 1083-1087.

[20] M. Alajarin, A. E. Aliev, A. D. Burrows, K. D. M. Harris, A. Pastor, J. W. Steed, D. R. Turner, Supramolecular Assembly via H-Bonds, Springer, Berlin, 2004.

[21] a) "Photochemistry and Photophysics of Coordination Compounds" Parts I \& II Topics in Curreent Chemistry, Volumes 280 and 281 Edited by V. Balzani (Universit di Bologna, Italy) and S. Campagna, (University of Messina, Italy), Springer, Berlin, Heidelberg, Germany, 2007; Part I: ISBN 978-3-540-73346-1, 273 pages, and Part II: ISBN 978-3-540-73348-5, 327 pages; b) V. W.-W. Yam, K. M.-C. Wong, Chem. Commun. 2011, 47, 11579- 11592.

[22] a) E. L. Que, D. W. Domaille, C. J. Cahng, Chem. Rev. 2008, 108, 1517-1549; b) M. D. Allendorf, C. A. Bauer, R. K. Bhakta, R. J. T. Houk, Chem. Soc. Rev. 2009, 38, 1330-1352; c) C. R. Goldsmith, S. J. Lippard, Inorg. Chem. 2006, 45, 555-561; d) A. Ajayaghosh, P. Carol, S. Sreejith, J. Am. Chem. Soc. 2005, 127, 14962-14963; e) A. Visscher, S. Bachmann, C. Schnegelsberg, T. Teuteberg, R. A. Mata, D. Stalke, Dalton Trans. 2016, 45, 5689-5699.

[23] a) Z. Dai, J. W. Canary, New J. Chem. 2007, 31, 1708-1718; b) B. Valeur, I. Leray, Coord. Chem. Rev. 2000, 205, 3-40. 


\section{Legends to figures}

Scheme 1. Schematic outline of the synthesis of complexes 1-4.

Figure. 1 ORTEP drawing of [Zn(m-Pip)2(3-Phpy)]2 (1) and [Zn(m-Pip)2(4-Phpy)]2 (2) (left: $50 \%$ probability amplitude displacement ellipsoids are shown.

Figure. 2 ORTEP drawing of [Cd (m-Pip)(Pip)(3-Phpy)2]2 (3) and [Cd (m-Pip)(Pip)(4-Phpy)2]2 (4)

(left: compound 1 right: compound 2), showing all non-hydrogen atoms and the atom numbering scheme; $50 \%$ probability amplitude displacement ellipsoids are shown.

Figure. 3 3D supramolecular layer stabilized by hydrogen bond interactions in compound 1, projection on the ab plane. Hydrogen atoms not participant in intermolecular interactions omitted for clarity.

Figure. 4 3D supramolecular interactions of compound 2 showing contacts expanding on the a and c directions. Hydrogen atoms not participant in intermolecular interactions omitted for clarity.

Figure. $53 \mathrm{D}$ supramolecular interactions of compound 3 showing contacts expanding on the $\mathrm{a}, \mathrm{b}$ and $\mathrm{c}$

Figure. $63 \mathrm{D}$ supramolecular interactions of compound 4 stabilized by hydrogen bonds, projection on the plane bc plane. Hydrogen atoms not participant in intermolecular interactions omitted for clarity.

Figure. 7 1HNMR spectra of compounds [Zn(m-Pip)2(3-Phpy)]2 (1), [Zn(m -Pip)2(4-Phpy)]2 (2),

Figure. 8 Emission spectra of [Zn(m-Pip)2(3-Phpy)]2 (1), [Zn(m -Pip)2(4-Phpy)]2 (2), [Cd(mPip)(Pip)(3-Phpy)2]2 (3) and [Cd(m-Pip)(Pip)(4-Phpy)2]2 (4) as well as the free ligand (HPip) in the 
a)<smiles>O=C(O)c1ccc2c(c1)OCO2</smiles>

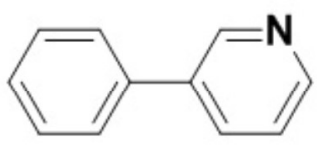<smiles>c1ccc(-c2ccncc2)cc1</smiles>

b) $\left[\mathrm{Zn}\left(\mathrm{MeCO}_{2}\right)_{2} \cdot 2 \mathrm{H}_{2} \mathrm{O}\right]+$ HPip

$\stackrel{\text { 4-Phpy }}{\longrightarrow}\left[\mathrm{Zn}(\mu-\mathrm{Pip})_{2}(4-\mathrm{Phpy})\right]_{2}$

c) $\left[\mathrm{Cd}\left(\mathrm{MeCO}_{2}\right)_{2} \cdot 2 \mathrm{H}_{2} \mathrm{O}\right]+$ HPip 


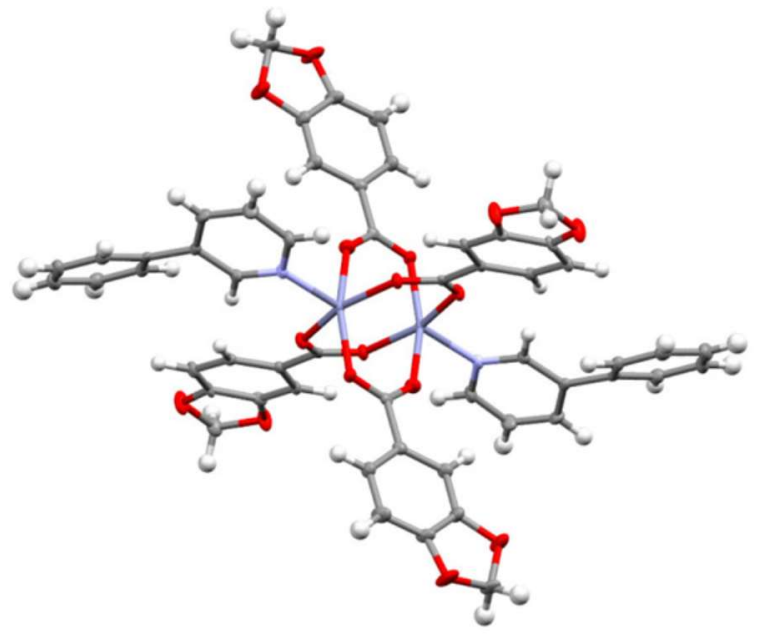

(1) $\left[\mathrm{Zn}(\mu \text {-Pip) })_{2}(3-\mathrm{Phpy})\right]_{2}$

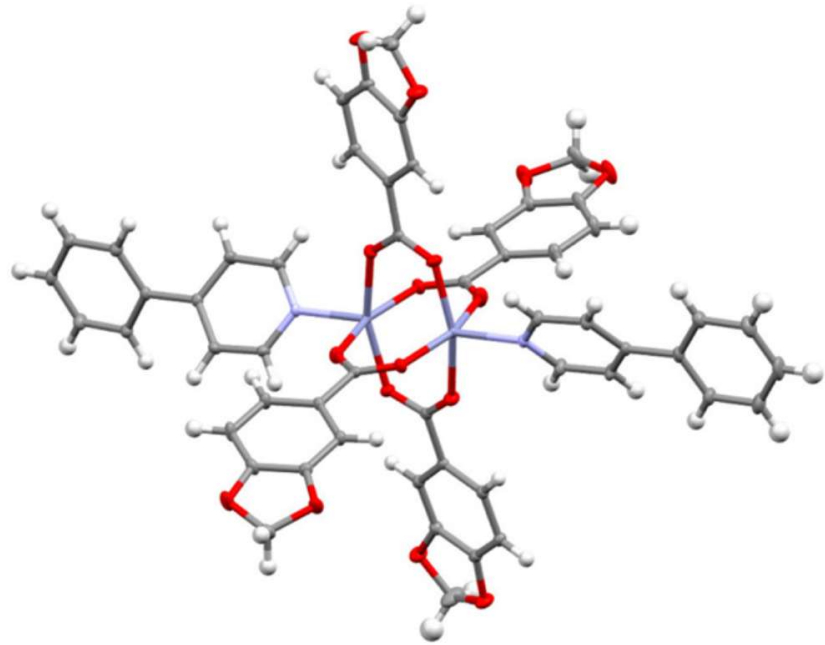

(2) $\left[\mathrm{Zn}(\mu \text {-Pip })_{2}(4-\mathrm{Phpy})\right]_{2}$ 


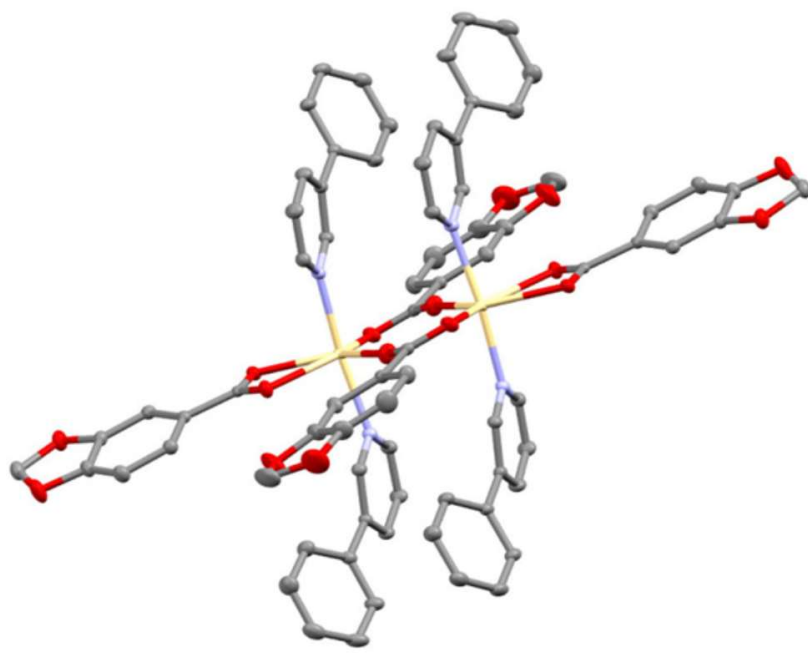

369

370
FIGURE 2

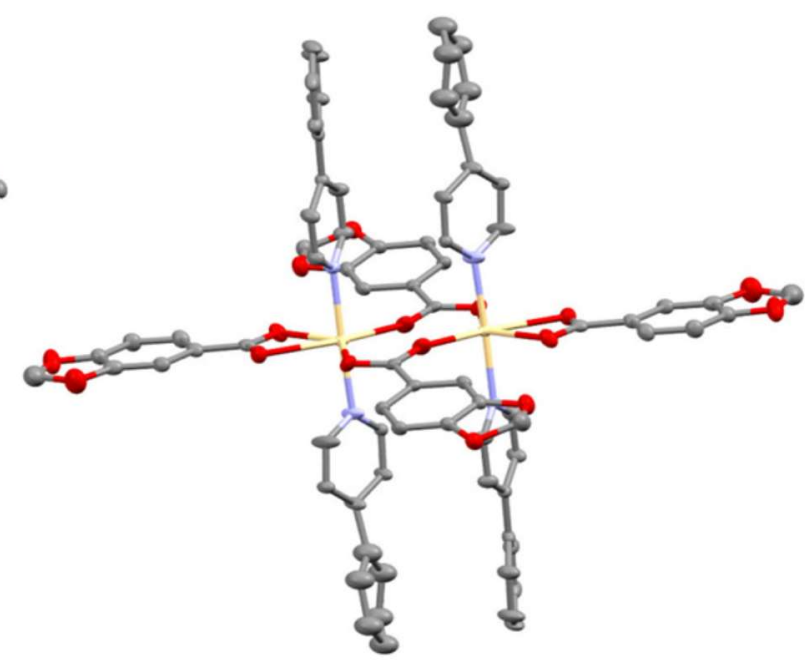

(4) $\left[\mathrm{Cd}(\mu \text {-Pip)(Pip)(4-Phpy) })_{2}\right]_{2}$ 
FIGURE 3

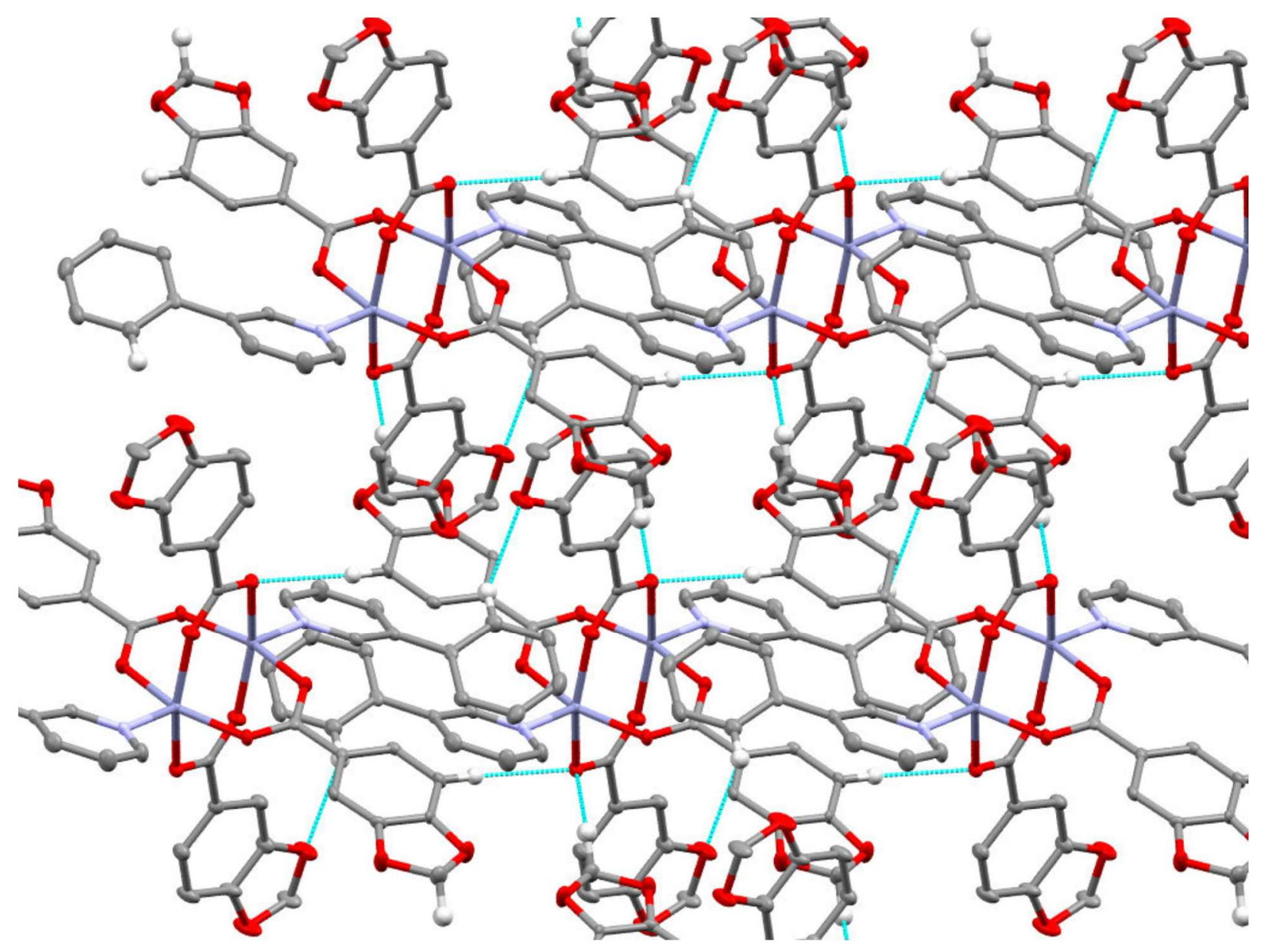

375 
FIGURE 4

377

378

379
380

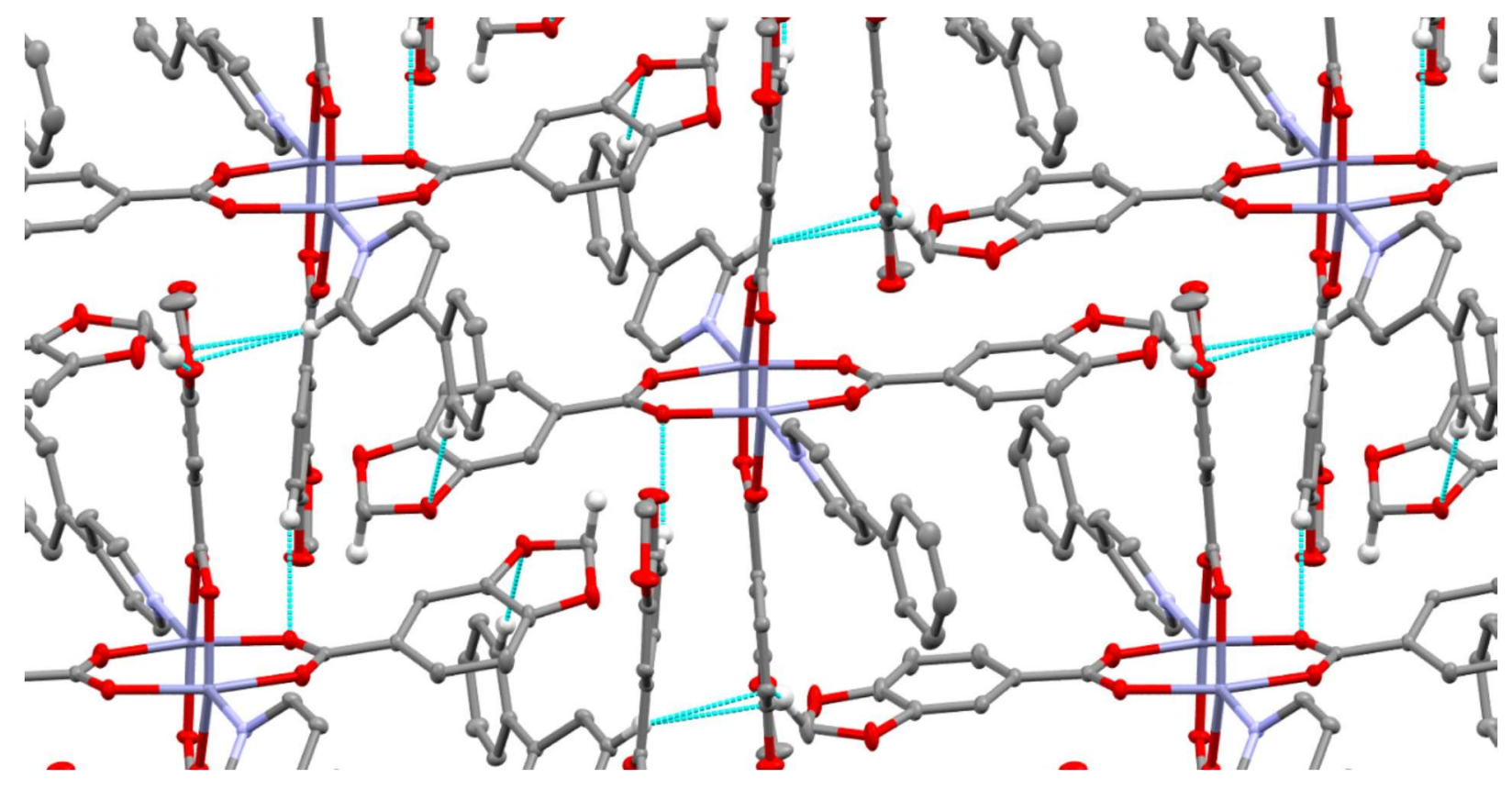

381

382 


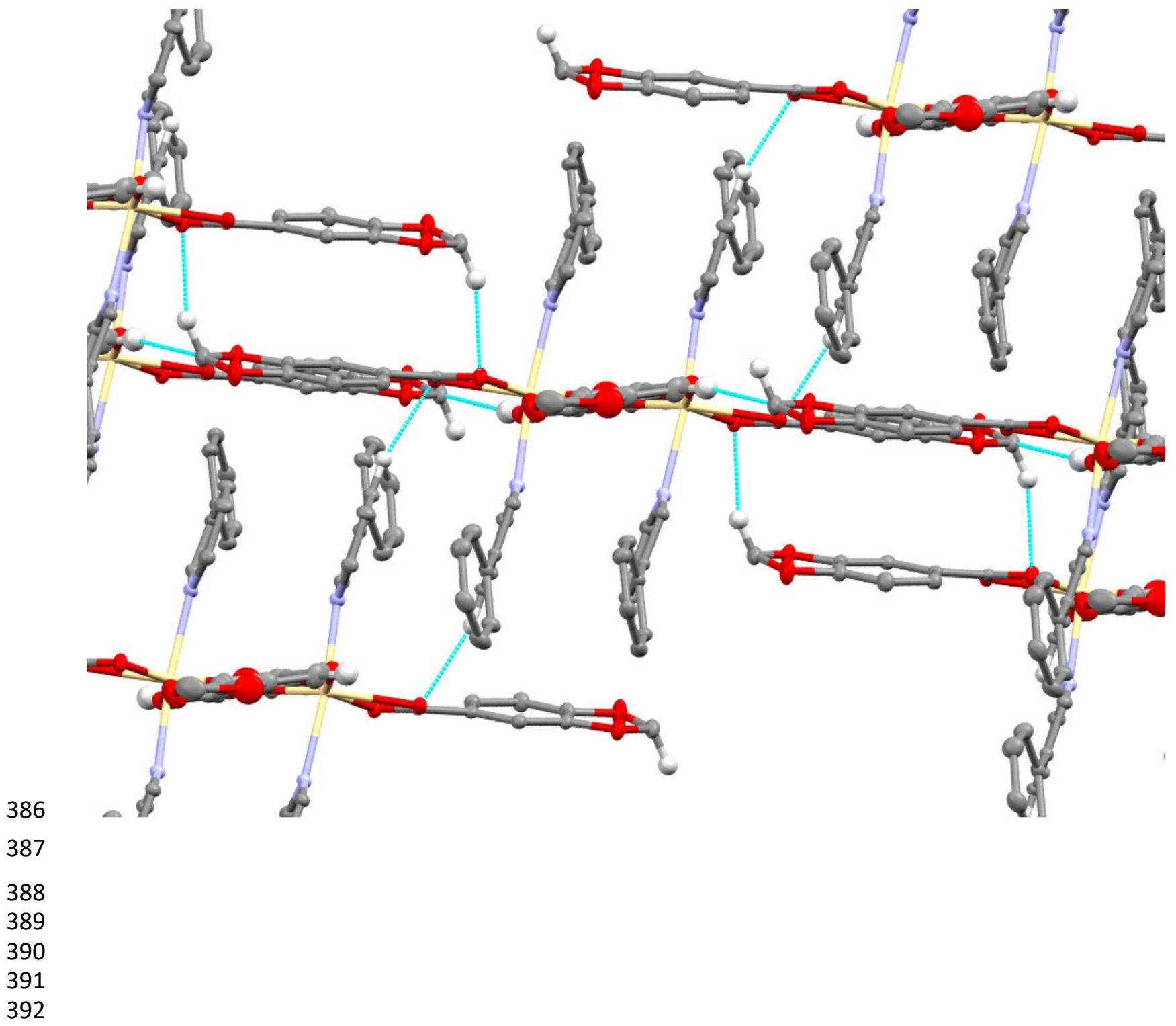




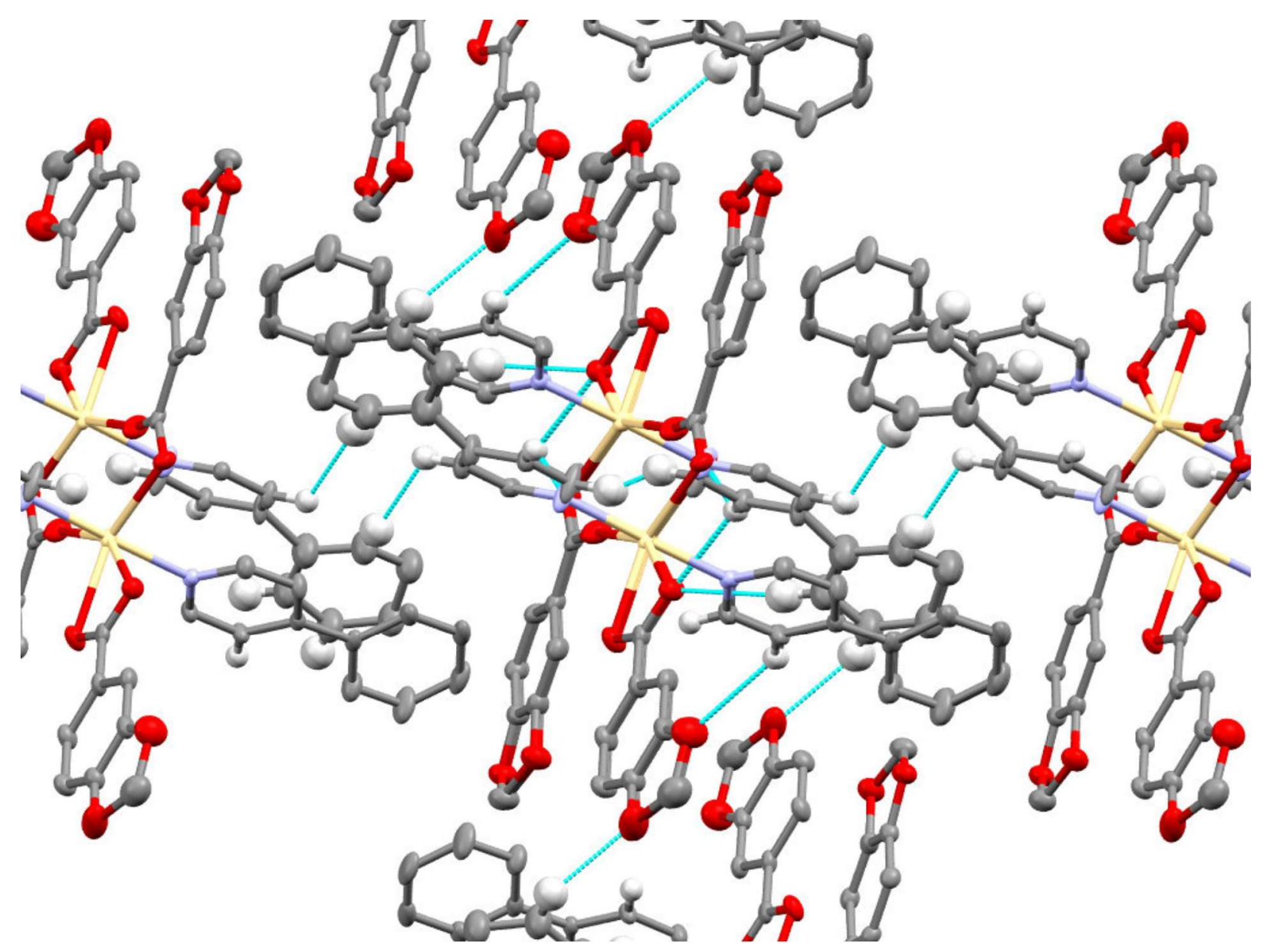

397 
400

401
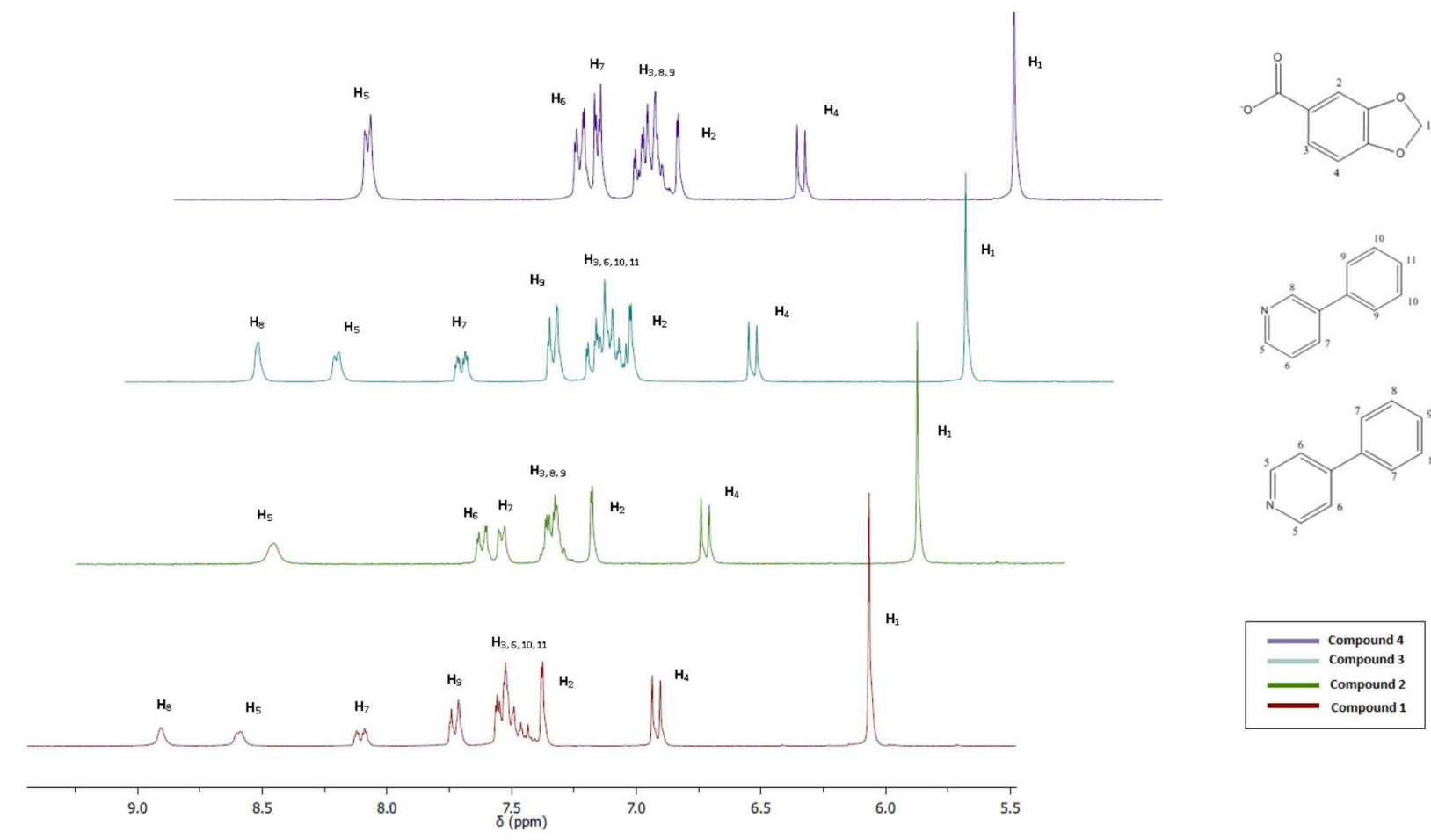

402

403

404 


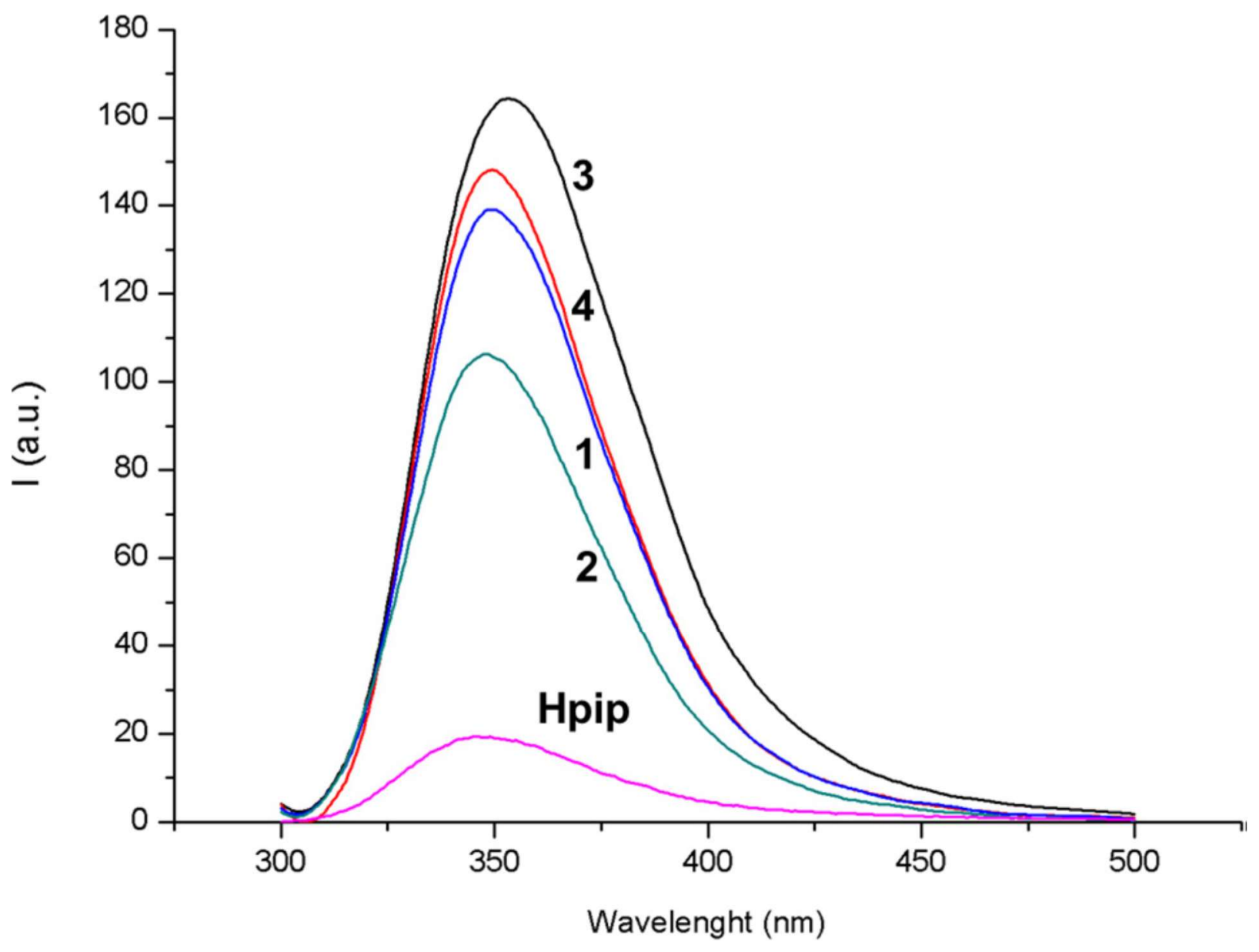


410 Table 1 Selected bond lengths ( $\square$ ) and bond angles (8) for complexes 1-4

\begin{tabular}{|c|c|c|c|c|c|c|c|}
\hline 1 & & 2 & & 3 & & 4 & \\
\hline $\operatorname{Zn}(1)-O(5)$ & $2018(3)$ & $\mathrm{Zn}(1) \mathrm{O}(5)$ & $20092(10)$ & $\mathrm{Cd}(1) \mathrm{O}(5)$ & $22967(9)$ & $C d(1) O(1)$ & $22802(11)$ \\
\hline $\operatorname{Zn}(1)-O(6)=1$ & $2023(3)$ & $\mathrm{Zn}(1) \circ(9)$ & $20244(9)$ & $C d(1) O(6)=1$ & $23095(10)$ & $\operatorname{Cd}(1) \mathbb{N}(1)$ & $22984(12)$ \\
\hline $\operatorname{Zn}(1)-N(1)$ & $2045(3)$ & $\mathrm{Zn}(1) \mathrm{N}(1)$ & $20396(11)$ & $\operatorname{Cd}(1)+N(2)$ & $23099(10)$ & $C d(1) N(2)$ & $23171(13)$ \\
\hline $\operatorname{Zn}(1)-\alpha(1)$ & $2054(3)$ & $\mathrm{Zn}(1) \mathrm{O}(1)$ & $20420(10)$ & $\operatorname{Cd}(1)+N(1)$ & $2.3214(10)$ & $C d(1) \circ(2)=1$ & 23401 (11) \\
\hline $\mathrm{Zn}(1)-\alpha(2) \neq 1$ & $2077(3)$ & $\mathrm{Zn}(1) \mathrm{O}(13)$ & $20614(10)$ & $C d(1) O(2)$ & $23659(9)$ & $C d(1) O(b)$ & $23490(11)$ \\
\hline $\mathrm{Zn}(1)-\mathrm{Zn}(1)=1$ & $29253 / 9)$ & $\mathrm{Zn}(1)-\mathrm{Zn}(2)$ & $29692(2)$ & $C d(1) O(1)$ & $24267(9)$ & $C d(1) O(5)$ & $24257(12)$ \\
\hline$\alpha(5)-Z n(1)-O(6)=1$ & $16033(11)$ & $\alpha(5)-\operatorname{Zn}(1)-O(9)$ & $91.85(4)$ & $O(5)-C d(1)-O(6)=1$ & $12866(4)$ & $\mathrm{O}(1)-\mathrm{Cd}(1) \mathrm{N}(2)$ & $87.13(5)$ \\
\hline$\alpha(S) Z \mathrm{Zn}(1)-N(1)$ & $99.25(12)$ & $\mathrm{O}(5)-\mathrm{Zn}(1)-\mathrm{N}(1)$ & $100.04 / 4)$ & $O(5)-C d(1)-N(2)$ & $94.50(4)$ & $N(1) C d(1) N(2)$ & $17806(5)$ \\
\hline$\alpha(6)=1-Z n(1)-N(1)$ & $10003(12)$ & $\alpha(9)-\operatorname{Zn}(1)-N(1)$ & $106.63 / 4)$ & $O(6)=1-C d(1)-N(2)$ & $8534 / 4)$ & $O(1)-C d(1)-(2)=1$ & $12523(4)$ \\
\hline$\alpha(s)=2 n(1)-\alpha(1)$ & $88.84(11)$ & $\alpha(5)-\operatorname{Zn}(1)-\alpha(1)$ & $160 \operatorname{as}(4)$ & $\operatorname{Os}(5) \cdot C d(1)-N(1)$ & $87.51(4)$ & $N(1) C d(1) O(2) \approx 1$ & $9360(4)$ \\
\hline$\left.\alpha(6)=1-Z n(1)-\alpha_{1}\right)$ & $8844(11)$ & $O(9)-\operatorname{Zn}(1)-O(1)$ & 8s. $11(4)$ & $O(5)=1-C d(1)-N(1)$ & $88.80(4)$ & $N(2) \subset d(1) O(2)=1$ & $86.14(5)$ \\
\hline$N_{(1)} \cdot \operatorname{Zn}(1)-\alpha_{(1)}$ & $109.30(12)$ & $N(1)-Z n(1) O(1)$ & $99.08(4)$ & $\mathrm{N}(2)-(d(1) \mathrm{N}(1)$ & $17397(4)$ & $O(1)-C d(1) O(6)$ & $15192(4)$ \\
\hline$\alpha(5)-Z n(1)-\alpha(2)=1$ & $89.90(11)$ & $\alpha(5) \cdot 2 \mathrm{Zn}(1)-\alpha(13)$ & $87.22(4)$ & $\alpha(5)-C d(1)-O(2)$ & $90.56(3)$ & $N(1) C d(1) O(6)$ & $9213(4)$ \\
\hline$\alpha(6) \div 1-Z n(1)-O(2)=1$ & $86.25(12)$ & $O(9) \cdot \operatorname{Zn}(1)-O(13)$ & $157.52(4)$ & $O(6)=1-C d(1)-O(2)$ & $14069(3)$ & $N(2)(d(1) \circ(6)$ & $8974(5)$ \\
\hline$N(1)-Z n(1)-\alpha(2) \approx 1$ & $90.07(12)$ & $N(1)-Z n(1) O(13)$ & $95.63: 4)$ & $N(2)-C d(1) O(2)$ & $95.20(3)$ & $O(2)=1-C d(1) \circ(6)$ & $82.31(4)$ \\
\hline$\alpha(1)-Z n(1)-\alpha(2)=1$ & $160.54(11)$ & $\alpha(1) \cdot \operatorname{Zn}(1)-\alpha(13)$ & $85.29(5)$ & $N(1)-C d(1) O(2)$ & $90.67(3)$ & $\mathrm{O}(1) \cdot C d(1) \mathrm{O}(5)$ & $9682(4)$ \\
\hline$\alpha(5)-Z n(1)-Z n(1)=1$ & $81.33(8)$ & $O(5)-\operatorname{Zn}(1)-\operatorname{Zn}(2)$ & $85.80(3)$ & $\alpha(5)-C d(1)-\alpha(1)$ & $145.14(3)$ & $N(1) C d(1) O(5)$ & $90.19(4)$ \\
\hline$\alpha(6)=1-Z n(1)-Z n(1)=1$ & $79.22(8)$ & $\alpha(9)-Z n(1)-Z n(2)$ & $87.41(3)$ & $\alpha(5)=1-C d(1)-Q_{(1)}$ & $85.60(3)$ & $N(2) C d(1) O(5)$ & $9129(5)$ \\
\hline$N(1)-\operatorname{Zn}(1)-\operatorname{Zn}(1)=1$ & $160.24 / 9)$ & $N(1)-Z n(1)-Z n(2)$ & $164.47(3)$ & $N(2)-C d(1) O(1)$ & $9464(3)$ & $O(2) \approx 1-C d(1)-(5)$ & $13760(4)$ \\
\hline$\alpha(1)-Z n(1)-Z n(1)=1$ & $90.45: 8)$ & $\alpha(1)-Z n(1)-Z n(2)$ & $74.26(3)$ & N(1)-Cd(1)o(1) & $87.00(3)$ & $O(6)-C d(1) O(5)$ & $55.34(4)$ \\
\hline$\alpha(2)=1-Z n(1)-Z n(1)=1$ & $70.17(8)$ & $O(13)-\operatorname{Zn}(1)-\operatorname{Zn}(2)$ & $70.12(3)$ & $\alpha(2)-(d(1)-\alpha(1)$ & $55.13(3)$ & $O(1)-C d(1) O(23)$ & $124.38(4)$ \\
\hline
\end{tabular}


416 Table 2 Supramolecular interactions (C $\left.\mathrm{H}^{\cdots} \mathrm{A}\right)$ for complexes 1-4

\begin{tabular}{|c|c|c|c|}
\hline & $\mathrm{C}-\mathrm{H}-\mathrm{O}[\mathrm{A}]$ & $\mathrm{C}-\mathrm{A}(\mathrm{A})$ & $\mathrm{C}-\mathrm{H}-\mathrm{N}[\mathrm{C}$ \\
\hline \multicolumn{4}{|l|}{1} \\
\hline$C(24)+H(24 B)-O(1)$ & $2486(3)$ & $3.196(3)$ & $128.25(12)$ \\
\hline$c(26)+H(26)-\alpha(1)$ & $2486(3)$ & $3331(3)$ & $148.02(13)$ \\
\hline $\begin{array}{l}c(7)+(7)-O(4) \\
2\end{array}$ & $2521(4)$ & $3.351(3)$ & $145.99(12)$ \\
\hline$C(12)+(12)-\alpha(9)$ & $2448(4)$ & $3.319(4)$ & $146.04(14)$ \\
\hline$c(50)+H(50)-\alpha(1)$ & $2524(4)$ & $3.471(4)$ & $174.23(12)$ \\
\hline$C(44)+H(44)-C g(1)$ & $3029(4)$ & $3.814(3)$ & $140.88(12)$ \\
\hline $\begin{array}{l}C(29)+H(29 A)-O(4) \\
3\end{array}$ & $2544(3)$ & $3.313(4)$ & $13434(12)$ \\
\hline$C(3)+H(3)-O, 2)$ & $2356(4)$ & $3.257(3)$ & $158.26(13)$ \\
\hline$C(28) H(28 B)-O(1)$ & $2468(3)$ & $3.411(4)$ & $15909(13)$ \\
\hline $\begin{array}{l}C(34)+H(34)-C(28) \\
4\end{array}$ & $2758(4)$ & $3.671(3)$ & $161.39(16)$ \\
\hline$C(18)+1(18)-\alpha(6)$ & $2547(4)$ & $3.491(3)$ & $172.50(14)$ \\
\hline$C(15)+1(15)-\alpha(6)$ & $2509(4)$ & $3.241(3)$ & $133.86(14)$ \\
\hline$C(15)+1(15)-\alpha(2)$ & $2491(4)$ & $3.281(3)$ & $140.64 / 12)$ \\
\hline$C(19)+(19)-\alpha 7)$ & $2455(3)$ & $3.232(4)$ & $138.93(13)$ \\
\hline$C(4)+H(4)-O / 3)$ & $2549(4)$ & $3.196(4)$ & $125.62(11)$ \\
\hline$C(16) H(16)-H(16)$ & $2093(3)$ & $2883(3)$ & $139.65(14)$ \\
\hline
\end{tabular}


Table 3. Crystallographic data for complexes 1-4

\begin{tabular}{|c|c|c|c|c|}
\hline & 1 & 2 & 3 & 4 \\
\hline $\begin{array}{l}\text { Formuk } \\
\text { Formuk Weight }\end{array}$ & $\begin{array}{l}\mathrm{C}_{2} \mathrm{H}_{4} \mathrm{~N}_{2} \mathrm{O}_{2} \mathrm{Zn} \\
110160\end{array}$ & $\begin{array}{l}C_{4} H_{2} N_{2} O_{2} Z n_{2} \\
110160\end{array}$ & $\begin{array}{l}C_{1} H_{2} N_{2} O_{1} C^{-d_{2}} \\
150604\end{array}$ & $\begin{array}{l}C_{1} H_{2} N_{2} O_{1} C_{2} \\
150604\end{array}$ \\
\hline Tempersture 100 & $100(2)$ & $100(2)$ & $99(2)$ & $100[2]$ \\
\hline Wavelength $(\dot{A})$ & 0.71073 & 0.71073 & a71073 & 071073 \\
\hline System, spnce group & Toclink, P(-1) & Tacin $\boldsymbol{c}_{,}, \mathrm{P}(-1)$ & Tridinic, $P(-1)$ & Tridinic, $P(-1)$ \\
\hline$a(k)$ & $9.9305(7)$ & $10.2580 / 5)$ & $11.4852(6)$ & $10.1058 / 4)$ \\
\hline$b(A)$ & $113696(9)$ & $11.1624 / 5)$ & $122328(6)$ & $128845(6)$ \\
\hline$c(\mathbb{A})$ & $12.4325(9)$ & $20.6960(9)$ & $124415(6)$ & $13,4330 / 6)$ \\
\hline$\alpha()$ & $108.417(3)$ & $94.805(2)$ & $112650(2)$ & $76.615(2)$ \\
\hline$\beta(1)$ & $101.933(3)$ & $103.054(2)$ & $94.508(2)$ & $86988(2)$ \\
\hline Yด & $110.311(3)$ & $99.605(2)$ & $99829(2)$ & $680470(10)$ \\
\hline$u\left(A^{n}\right) / Z$ & $116735(15) / 1$ & $2257.90(18) / 2$ & $1569.47(14) / 1$ & $157708(12) / 1$ \\
\hline $\mathrm{D}_{\mathrm{ak}}\left(\mathrm{g} \mathrm{cm}^{-3}\right) / \mu\left(\mathrm{mm}^{-3}\right)$ & $1.567 / 1.107$ & $1.620 / 1.145$ & $1593 / 0.756$ & $1.586 / 0.752$ \\
\hline$F(000)$ & 564 & 1128 & 764 & 764 \\
\hline Crystd size (mm') & $0.358 \times 0.282 \times 0.044$ & $0.273 \times 0.165 \times 0.141$ & $0.401 \times 0.22460 .207$ & $0.333 \times 0.22660 .151$ \\
\hline hali ranges & $\begin{array}{l}-12 \leq h \leq 12,-14 \leq k \leq 14, \\
-16 \leq k \leq 16\end{array}$ & $\begin{array}{l}-145 \mathrm{~h} \leq 14,-15 \leq \mathrm{k} \leq 15 \\
-2951 \leq 29\end{array}$ & $\begin{array}{l}-16 \leq h \leq 16,-17 \leq k \leq 17, \\
-17 \leq 1 \leq 17\end{array}$ & $\begin{array}{l}-14 \leq h \leq 14,-18 \leq k \leq 18 \\
-19 \leq 1 \leq 19\end{array}$ \\
\hline 29 Range $(19$ & 2136 to 27.616 & 2009 to 30.651 & 2295 to 30619 & 2174 to 30769 \\
\hline Reflections & $19059 / 5290$ & $127839 / 13866$ & 785799623 & $66755 / 9701$ \\
\hline collaxted/unique/ [Re] & {$[R(i n t)-0.0616]$} & $R(i n t)-0.0367]$ & $(A / i n t)-0.0256]$ & {$[$ (R/int) -0.0256$]$} \\
\hline Completaness to $\theta$ (96) & 99.2 & 99.9 & 999 & 996 \\
\hline Absomson correctson & Semiempiteal & Sem-emprical & Semiempircal & Semiempircal \\
\hline Max and min trane. & 0.7456 and 0.5382 & 0.7461 and 0.6946 & 0.7461 snd 0.6843 & 0.7461 and 0.6892 \\
\hline Data/restrains/ponmears & $5290 / a / 334$ & $13866 / 2 / 667$ & $9623 / 4 / 442$ & $9701 / 9 / 490$ \\
\hline Goodhessofit on $\mathrm{F}^{3}$ & 0.877 & 1.081 & 1.138 & 1074 \\
\hline Final $R$ indices $\|>2 \sigma 00$ & $R_{1}-0.0513, w R_{2}-0.1191$ & $R_{1}=0.0288, w R_{2}-0.0741$ & $R_{1}-0.0273, w R_{2}-0.0596$ & $R_{1}-0.0283$, whe -0.0757 \\
\hline 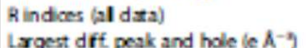 & $\begin{array}{l}R_{1}-0.1122, w R_{2}-0.1554 \\
\pm 0.603,0.11\end{array}$ & $\begin{array}{l}R_{1}=0.0374, w R_{2}-0.0503 \\
+0.547_{2}=0.506\end{array}$ & $R_{1}-0.0250, w R_{2}-0.0613$ & $\begin{array}{l}R_{1}-0.0301, w R_{2}-0.0773 \\
+2738\end{array}$ \\
\hline
\end{tabular}

